\title{
Shift Worker Disease with Obstructive Sleep Apnea
}

\author{
1Dipti Gothi, ${ }^{2}$ Sonam Spalgais
}

\begin{abstract}
Shift work employment involves guidelines to be followed to protect employees from getting adverse effects on health. There are no proper guidelines that are made and followed in India about the same. Our patient who was covered under employee State Insurance Scheme was required to work continuously during the night for 5 years. He not only developed shift work disease but also had an overlap of obstructive sleep apnea (OSA). The adverse consequences made him suffer from severe depression for 2 years even after quitting the night shift. Strict guidelines are required to be laid down and followed for companies, which require night shift working.
\end{abstract}

Keywords: Circadian rhythm, Obstructive sleep apnea, Shift worker disease.

How to cite this article: Gothi D, Spalgais S. Shift Worker Disease with Obstructive Sleep Apnea. Indian Sleep Med 2018;13(4):71-73.

\section{Source of support: Nil \\ Conflict of interest: None}

\section{INTRODUCTION}

Shift work is a work schedule involving irregular or unusual hours, compared to the normal daytime work schedule. ${ }^{1}$ Shift worker disease (SWD) is a condition that is triggered by circadian misalignment and which results in insomnia and/or excessive sleepiness. There is substantial variability intolerance for and adaptation to shiftwork, and roughly one of five shift workers develops SWD. ${ }^{2}$ The prevalence of a general sleep disturbance is significantly higher in SWD than for day workers. ${ }^{3} \mathrm{SWD}$ are also known to have overlappingsleep disorders more commonly than day workers. The reduced sleep duration and recurrent circadian disruption induced by night shift work adversely affect cardiovascular regulation, leading to increased risk of calcification of the coronary arteries, stroke, and death. ${ }^{4-7}$ Even after resuming to normal work hours the sleep disturbance caused by previous shift

\footnotetext{
${ }^{1}$ Professor, ${ }^{2}$ Assistant Professor

${ }^{1}$ Department of Pulmonary Medicine, Employees State Insurance Post Graduate Institute of Medical Sciences and Research, Basaidarapur, New Delhi, India

${ }^{2}$ Department of Pulmonary Medicine, Vallabhbhai Patel Chest Institute, Basaidarapur, New Delhi, India
}

Corresponding Author: Dipti Gothi, Professor, Pulmonary Medicine, Employees State Insurance Post Graduate Institute of Medical Sciences and Research, Basaidarapur, New Delhi, India, e-mail: diptigothi@gmail.com work experience remain for the longer duration. We are reporting a case of shift worker disease in combination with obstructive sleep apnea and chronic obstructive pulmonary disease (COPD).

\section{CASE REPORT}

A 61-year-old man presented with breathlessness modified medical research council (mMRC) grade II and cough with expectoration of 1-year duration. He was achronic bidi smoker and smoked two bundles/day for the last 45 years. He was a watchman in a garment factory by occupation with night shift duty for 5 to 6 years, daily without a single day break. He used to sleep for 5 to 6 hours during the daytime and complained of snoring and choking during sleep. He had a history of excessive daytime/nocturnal sleepiness, fatigue during the day as well as night, non-refreshing sleep, frequently fragmented sleep by choking and urination 3 to 4 times when he slept during the day. He also had decreased alertness, mood and personality changes with neurocognitive dysfunction. The patient's Epworth sleepiness scale was 12 with a STOP-BANG score of five. On examination his pulse was $96 /$ minute, $\mathrm{SpO}_{2}$ was $98 \%$ on room air, and blood pressure was $114 / 78 \mathrm{mmHg}$. His neck circumference was $38 \mathrm{~cm}$ (14.9 inches), waist circumference was 43 inches, and body mass index (BMI) was $29.5 \mathrm{~kg} / \mathrm{m}^{2}$. On oral examination, his Mallampatti score was four. Respiratory examination revealed bilateral vesicular breath sound with bilateral rhonchi. Other systemic examination was normal. Investigation showed hemoglobin $15 \mathrm{gm} \%$; total leucocyte count -5300 with $56 \%$ neutrophil and $44 \%$ lymphocytes. All routine biochemical investigation was normal. Chest radiograph, electrocardiograph, and two-dimensional echocardiography were also normal. His arterial blood gas was: $\mathrm{PH}-7.35, \mathrm{PaCO}-42 \mathrm{mmHg}$, $\mathrm{PaO} 2-78 \mathrm{mmHg}$, HCO3-24, and $\mathrm{SaO} 2-93 \%$. Spirometry revealed severe obstructive abnormality. He was diagnosed as a COPD Global Initiative for Chronic Obstructive Lung Disease (GOLD) stage III and started with bronchodilator treatment as per guideline.

His daytime symptoms could have been due to SWD or OSA or both with COPD. A day time sleep study of this patient was done wherein he slept for about 4 hours, showing apnea-hypopnea index (AHI)-10/hour, saturation remained above $95 \%$ throughout the study time, with no rapid eye movement (REM) sleep reported. So, he was also diagnosed as OSA with COPD. He was titrated for continues positive airway pressure (CPAP) on the next 
day, and he tolerated the CPAP well. Therefore, the patient was advised CPAP @ $9 \mathrm{~cm}$ of $\mathrm{H}_{2} \mathrm{O}$ with COPD treatment. The symptoms did not completely disappear with CPAP treatment except for slight improvement in sleep. So he was diagnosed to have SWD too as per International Classification for a Sleep Disorder (ICSD)-3 guidelines.

When he followed up after quitting the job, he had severe insomnia and depression. He avoided using CPAP as he was hardly sleeping resulting in the psychological disturbance. So, we treated him with behavioral therapy, and ramelteon was given for insomnia, but both the treatments were not completely effective. He required both selective serotonin reuptake inhibitors (SSRI) and hypnotic drugs for controlling the depression. The hypnotic drugs worsened OSA and COPD leading to frequent exacerbations with recurrent hospitalizations. After one and half years of quitting the night shift work job the vicious circle of depression, OSA and insomnia were controlled.

\section{DISCUSSION}

We have described COPD and OSA overlap disorder complicated with SWD. The shiftwork patients are known to have severe addictions, ${ }^{2,8}$ which led to COPD which along with OSA and SWD led to severely disrupted daytime sleep (Fig. 1). Shift work occupation is common worldwide, which ranges from 15 to $25 \%$., 10 There is a lack of published data from India on shift work and shift work-related disease. So, the chances of mis/underdiagnosis of SWD is common unless detail history and regular follow-up of the patient. As per the best of our knowledge, this is the first case of circadian rhythm,shift worker disease from India.

Shift workers disorder occur due to circadian disruption. Circadian rhythm disruption is dyssynchrony between internal circadian rhythm and environmental circadian rhythm due to irregular work hours. ${ }^{2,11,12}$ Internal circadian rhythm is a cellular clock run on a cycle that

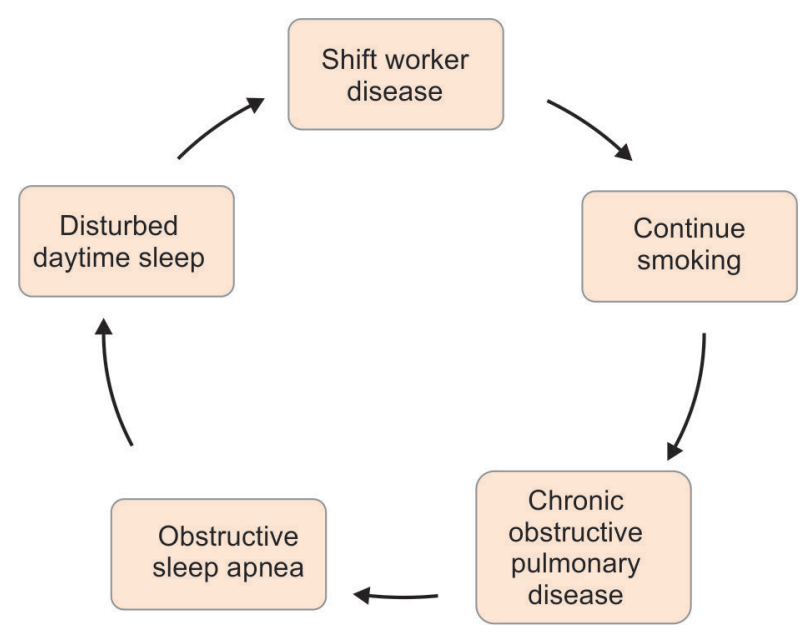

Fig. 1: Vicious cycle triad of COPD, OSA and SWD is close to 24 hours (earth's revolution). All physiological functions most notably sleep and wake cycles, exhibit circadian rhythmicity. Circadian rhythms are endogenous and persist in the absence of environmental time cues. The suprachiasmatic nucleus (SCN) is the master clock that synchronizes the earth's 24-hour period via light-dark exposure with internal circadian rhythm. ${ }^{12,13}$ Two of the best rhythms driven by the SCN are the body temperature cycle and the production of melatonin. ${ }^{12-14}$ Melatonin helps in initiation and amintainance of sleep.

The shift work disorder is one type of circadian rhythm sleep wake disorders. ${ }^{15}$ The diagnosis of SWD require diagnostic criteria which consist of the following $^{2,15,16}$ (a) insomnia and/or excessive sleepiness is present and temporally associated with a work schedule that regularly overlaps the usual time for sleep; (b) symptoms are associated with the shift work schedule for duration > 1 month; (c) sleep log or actigraphy monitoring (with sleep diaries) for $>7$ days demonstrates circadian and sleep-time misalignment; (d) symptoms are not better explained by another sleep, medical, neurologic, or mental disorder, medication use, or substance use.

There is a lack of studies on SWD associated with OSA. The sleep deprivation itself can lead to or worsen OSA. The symptoms of nearly all main sleep disorders, thatis, insomnia, circadian rhythm sleep-wake disorder, parasomnia, hypersomnolence, and leg movement disorder are higher in shift worker patients. ${ }^{3}$ The OSA is seen in nearly 30 to $35 \%$ of shift workers. There is the significantly higher severity of OSA symptoms during daytime sleep after a night shift with severe AHI, decrease in subjective sleep quality, reduce REM sleep density, increase the frequency of micro-arousals, and desaturations in SWD with OSA compared to OSA alone. 2,17,18 These patients have worse mood neurocognitive deficit and a higher risk of the major coronary event due to the coexistenceof SWD and OSA. ${ }^{2,4,18}$

The long-term consequences of shift worker diseases have increased the risk of cardiovascular disease, cancer, anxiety, depression, diabetes,metabolic syndrome, sleep breathing disorders and cognitive impairment. ${ }^{2,4,19-21}$ They experience a higher level of job stress with reported problems in their social life and increased use of the sleeping pill, tranquilizer,more alcohol intake, and cigarette smoking. .,22 $^{2}$

Shift work is a vital component of the modern world. So, there is no cure for SWD. The various treatment options for SWD are a circadian adaptation, improving sleep, naps and pharmacological agents. ${ }^{2}$ The circadian adaptation is to reduce the circadian misalignment to enhance adaptation to the shift work schedule. The powerful external time cue (i.e., zeitgeber) for circadian adaptation is bright light exposure and melatonin. ${ }^{23,24}$ To improve sleep, the patients should practice good sleep hygiene, i.e., avoiding alcohol and caffeine before bed time 
and sleeping environment should be cool, dark, quiet, andclean. The behavioral strategy to improve sleep is to "anchor" sleep by creating a sleep period that overlaps on both work and nonwork days. ${ }^{2,25}$ Taking naps can help increase total sleep time, increase alertness and improve performance. Napping before and during shifts decreases, reaction time increases alertness and reduces fatigue. ${ }^{2,26}$ The various pharmacological agents use benzodiazepine/ non-benzodiazepine sedative hypnotic agents such as triazolam, temazepam, and zolpidem. Other food and drug administration (FDA) approved drug for treatment of SWD are modafinil and armodafinil. ${ }^{2,27,28}$

There is no strict guideline for shift worker in India. Many shift workers are suffering from SWD and they do not even know about their disease and its relation to shifting work schedule. This leads to job loss, social and financial burden of shift worker and their family. We advise making a proper and strict guideline, which can be followed by shift worker and their employers in India.

\section{REFERENCES}

1. Wang XS, Armstrong ME, Cairns BJ, Key TJ, Travis RC. Shift work and chronic disease: the epidemiological evidence. Occupational medicine. 2011 Mar 1;61(2):78-89.

2. Wickwire EM, Geiger-Brown J, Scharf SM, Drake CL. Shift work and shift work sleep disorder: clinical and organizational perspectives. Chest. 2017 May 1;151(5):1156-1172.

3. Kerkhof GA. Shift work and sleep disorder comorbidity tend to go hand in hand. Chronobiology international. 2018 Feb 1;35(2):219-228.

4. Barger LK, Rajaratnam SM, Cannon CP, Lukas MA, Im K, Goodrich EL, et al. Short sleep duration, obstructive sleep apnea, shiftwork, and the risk of adverse cardiovascular events in patients after an acute coronary syndrome. Journal of the American Heart Association. 2017 Oct 1;6(10):e006959.

5. Scheer FA, Hilton MF, Mantzoros CS, Shea SA. Adverse metabolic and cardiovascular consequences of circadian misalignment. Proceedings of the National Academy of Sciences. 2009 Mar 17;106(11):4453-4458.

6. Cappuccio FP, Cooper D, D'elia L, Strazzullo P, Miller MA. Sleep duration predicts cardiovascular outcomes: a systematic review and meta-analysis of prospective studies. European heart journal. 2011 Feb 7;32(12):1484-1492.

7. King CR, Knutson KL, Rathouz PJ, Sidney S, Liu K, Lauderdale DS. Short sleep duration and incident coronary artery calcification. Jama. 2008 Dec 24;300(24):2859-2866.

8. Trinkoff AM, Storr CL. Work schedule characteristics and substance use in nurses. American journal of industrial medicine. 1998 Sep;34(3):266-271.

9. Boisard P, Cartron D, Gollac M, Valeyre A. Time and work: duration of work. Publications Office of the European Union; 2003.

10. Lee S, McCann D, Messenger JC. Working time around the world. Geneva: ILO. 2007.

11. The international classification of sleep disorders: diagnostic and coding manual, ICSD-2. 2nd. Westchester, IL: American Academy of Sleep Medicine; 2005.

12. Zhu L, Zee PC. Circadian rhythm sleep disorders. Neurologic clinics. 2012 Nov 1;30(4):1167-1191.
13. Stephan FK, Zucker I. Circadian rhythms in drinking behavior and locomotor activity of rats are eliminated by hypothalamic lesions. Proceedings of the National Academy of Sciences. 1972 Jun 1;69(6):1583-1586.

14. Czeisler CA, Allan JS, Strogatz SH, Ronda JM, Sanchez R, Rios CD, Freitag WO, Richardson GS, Kronauer RE. Bright light resets the human circadian pacemaker independent of the timing of the sleep-wake cycle. Science. 1986 Aug 8;233(4764):667-671.

15. Sateia MJ. International classification of sleep disorders. Chest. 2014 Nov 1;146(5):1387-1394.

16. Edition F, American Psychiatric Association. Diagnostic and statistical manual of mental disorders. Arlington: American Psychiatric Publishing. 2013.

17. Kloepfer C, Riemann D, Nofzinger EA, Feige B, Unterrainer J, O\&rsquo R, Sorichter S, Nissen C. Memory before and after sleep in patients with moderate obstructive sleep apnea. Journal of Clinical Sleep Medicine. 2009 Dec 15;5(06):540548.

18. Drake CL, Roehrs T, Richardson G, Walsh JK, Roth T. Shift work sleep disorder: prevalence and consequences beyond that of symptomatic day workers. Sleep. 2004 Dec 1;27(8):1453-1462.

19. Karlsson B, Knutsson A, Lindahl B. Is there an association between shift work and having a metabolic syndrome? Results from a population based study of 27485 people. Occupational and environmental medicine. 2001 Nov 1;58(11):747-752.

20. Angerer P, Schmook R, Elfantel I, Li J. Night work and the risk of depression: A systematic review. Deutsches Ärzteblatt International. 2017 Jul;114(24):404.

21. Nena E, Katsaouni M, Steiropoulos P, Theodorou E, Constantinidis TC, Tripsianis G. Effect of shift work on sleep, health, and quality of life of health-care workers. Indian journal of occupational and environmental medicine. 2018 Jan;22(1):29.

22. Gordon NP, Cleary PD, Parker CE, Czeisler CA. The prevalence and health impact of shiftwork. American journal of public health. 1986 Oct;76(10):1225-1228.

23. Boivin DB, James FO. Light treatment and circadian adaptation to shift work. Industrial health. 2005;43(1):34-48.

24. Rajaratnam SM, Polymeropoulos MH, Fisher DM, Roth T, Scott C, Birznieks G, Klerman EB. Melatonin agonist tasimelteon (VEC-162) for transient insomnia after sleep-time shift: two randomised controlled multicentre trials. The Lancet. 2009 Feb 7;373(9662):482-491.

25. Minors DS, Waterhouse JM. Does 'anchor sleep'entrain circadian rhythms? Evidence from constant routine studies. The Journal of physiology. 1983 Dec 1;345(1):451-467.

26. Smith-Coggins R, Howard SK, Mac DT, et al. Improving alertness and performance in emergency department physicians and nurses:the use of planned naps. Ann Emerg Med. 2006;48(5):596-604.

27. Morgenthaler TI, Lee-Chiong T, Alessi C, Friedman L, Aurora RN, Boehlecke B, Brown T, Chesson Jr AL, Kapur V, Maganti $\mathrm{R}$, Owens J. Practice parameters for the clinical evaluation and treatment of circadian rhythm sleep disorders. Sleep. 2007 Nov 1;30(11):1445-1459.

28. Hart CL, Ward AS, Haney M, Foltin RW. Zolpidem-related effects on performance and mood during simulated nightshift work. Experimental and clinical psychopharmacology. 2003 Nov;11(4):259. 